\title{
Harmonic Mitigation in Three-Phase Power Networks with Photovoltaic Energy Sources
}

\author{
Mohammad Amin Chitsazan*, Andrzej M. Trzynadlowski \\ Department of Electrical and Biomedical Engineering, University of Nevada, Reno, USA \\ Email address: \\ chitsaazaan@gmail.com (M. A. Chitsazan),chin@unr.edu (A. M. Trzynadlowski) \\ ${ }^{*}$ Corresponding author
}

To cite this article:

Mohammad Amin Chitsazan, Andrzej M. Trzynadlowski. Harmonic Mitigation in Three-Phase Power Networks with Photovoltaic Energy Sources. American Journal of Electrical Power and Energy Systems. Vol. 6, No. 5, 2017, pp. 72-78. doi: 10.11648/j.epes.20170605.12

Received: July 31, 2017; Accepted: August 7, 2017; Published: August 23, 2017

\begin{abstract}
Energy systems based on photovoltaic (PV) cells have increased at a rapid pace. Therefore, power converters have been widely employed in power systems to enhance the quality and magnitude of the power drawn from renewable energy sources. An LCL filter for connection of an inverter to the grid is often used to reduce harmonics generated by the inverter. According to different design techniques, optimal parameters of LCL filter tend to vary in a wide range. This paper presents a new approach to an LCL filter. A phase shifting transformer placed in the structure of an LCL filter to minimize harmonic current. Methods and techniques described in this paper are particularly suitable for grid-connected PV power systems.
\end{abstract}

Keywords: Harmonic Mitigation, LCL Filters, PV Sources

\section{Introduction}

There is a widespread use of renewable energy in the distribution networks. The photovoltaic (PV) cells starts to have significant impacts to the power grid system. Therefore, more advanced filters, power electronic systems, and control solutions have to be introduced to improve the power quality, network reliability and stability [1-3].

Typically, photovoltaic (PV) cells are connected to the grid through multilevel voltage source inverters [4]. To mitigate the harmonic content of currents produced by power converters connected to the grid through multilevel voltage source inverters, a filter is needed between the inverter and the power grid. An inductor usually is used as the simplest solution. However, its large size and significant voltage drop are its disadvantageous. Therefore, an LCL passive filter is used to mitigate current harmonics caused by pulse width modulation. The LCL filters satisfy the standards for grid interconnection with smaller size and cost, comparing with a first-order L filter, particularly in high-power cases [5]. Moreover, due to the weight and size reduction, higher attenuation and cost savings are its additional advantages. Application of LCL filters in grid-connected inverters and PWM rectifiers is discussed in [6-7]. However, the LCL filter may cause instability of a closed-loop control system, and trigger resonances between the inverter and the grid. To meet harmonic constraints, as defined by standards such as IEEE519 [8], and IEEE-1547 [9], a lower switching frequency is achieved by harmonic attenuation. Moreover, mathematical models must be defined to design the filter effectively. Several suggested solutions have been proposed including active damping [10], passive damping [11], parameter choice to suppress possible resonances in the filter [12], and state feedback control with state observer [13]. Passive damping method is implemented by inserting a resistor in series with the capacitor in the filter. Although it is considered as a simple, effective, and reliable solution, it causes extra power loss and deteriorates the high-frequency harmonic attenuation ability of the filter.

To overcome these drawbacks, an RC circuit is inserted in parallel with the capacitor of the filter. However, to compare with an undamped filter, the high-frequency harmonic attenuation of the passively damped LCL filter deteriorates. Stability of the LCL filter and current control techniques in the LCL filter design are studied in [14]. In this paper, a phase shifting transformer (PST) is added into the LCL structure. PSTs allow an economical and reliable control of electricity transfer over parallel conduits of electricity. The power flow is controlled by changing the phase-shift angle 
between the PST source- and load-side voltages [15]. However, in many cases the angles are controlled by humans. Reference [16] presents a method to control the phase angle by a voltage source converter. Phase shifting transformers are used into passive filter structures to mitigate the harmonic currents [17-18].

This paper shows that harmonic currents and the THD can be adjusted by changing the phase angle of the PST. The objective is to optimize its design for minimizing the total harmonic distortion (THD) of the filtered current. The PST is inserted in series with the capacitor, and changing the phase angle of the PST makes the filter controllable. Adjusting the phase angle of the PST allows significant reduction of the THD. The PST can also be used for harmonic mitigation, with no need for adjustment of the LCL parameters, when the switching frequency of the inverter or load changed.

The paper is organized as follows. The proposed filter is presented in Section II. Filter design procedure is discussed in Section III. Simulation of a case study is described in Section IV, and Section V concludes the considerations.

\section{Proposed Filter}

Figure 1 illustrates the proposed LCL filter, where $L_{G}$ is the grid-side inductor, $L_{I}$ is the inverter side inductor, $C_{f}$ is a capacitor with a series $R_{f}$ damping resistor, and $V_{I}$ and $V_{G}$ are the inverter and grid voltages. The inverter output current, the capacitor current, and the grid current are denoted by $i_{I}, i_{c}$ and $i_{G}$, respectively. The transfer function is $H_{L C L}=i_{G} / V_{I}$, where the grid voltage is assumed to be an ideal voltage source capable of damping all the harmonic frequencies. If one sets $V_{G}=0$, which implies a current-controlled inverter, the transfer functions of the LCL filter with and without and the phase shifting transformer are defined as (1) and (2) respectively. Figure 2 shows the Bode plots of the PST-LCL filter for different phase angles. The insertion of a phase shifting transformer eliminates the gain spike, smoothing the overall response and rolling-off between $-75^{\circ}$ and $-325^{\circ}$, instead of the $-180^{\circ}$ at high frequencies.

$$
\begin{gathered}
H_{P S T-L C L}(s)=\frac{C_{f} \cdot R_{f} \cdot s+1}{L_{I} \cdot C_{f} \cdot L_{G} \cdot s^{3} \angle \Phi+C_{f} \cdot\left(L_{1}+L_{2}\right) \cdot R_{f} \cdot s^{2}+\left(L_{I}+L_{G}\right) \cdot s} \\
H_{L C L}(s)=\frac{C_{f} \cdot R_{f} \cdot s+1}{L_{I} \cdot C_{f} \cdot L_{G} \cdot s^{3}+C_{f} \cdot\left(L_{1}+L_{2}\right) \cdot R_{f} \cdot s^{2}+\left(L_{I}+L_{G}\right) \cdot s}
\end{gathered}
$$

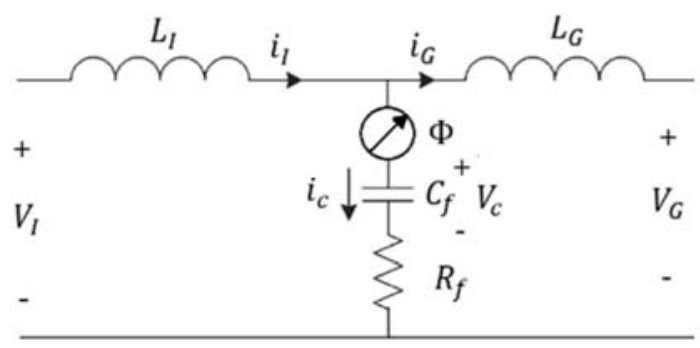

Figure 1. The proposed LCL filter (PST-LCL).

\section{Bode Diagram}
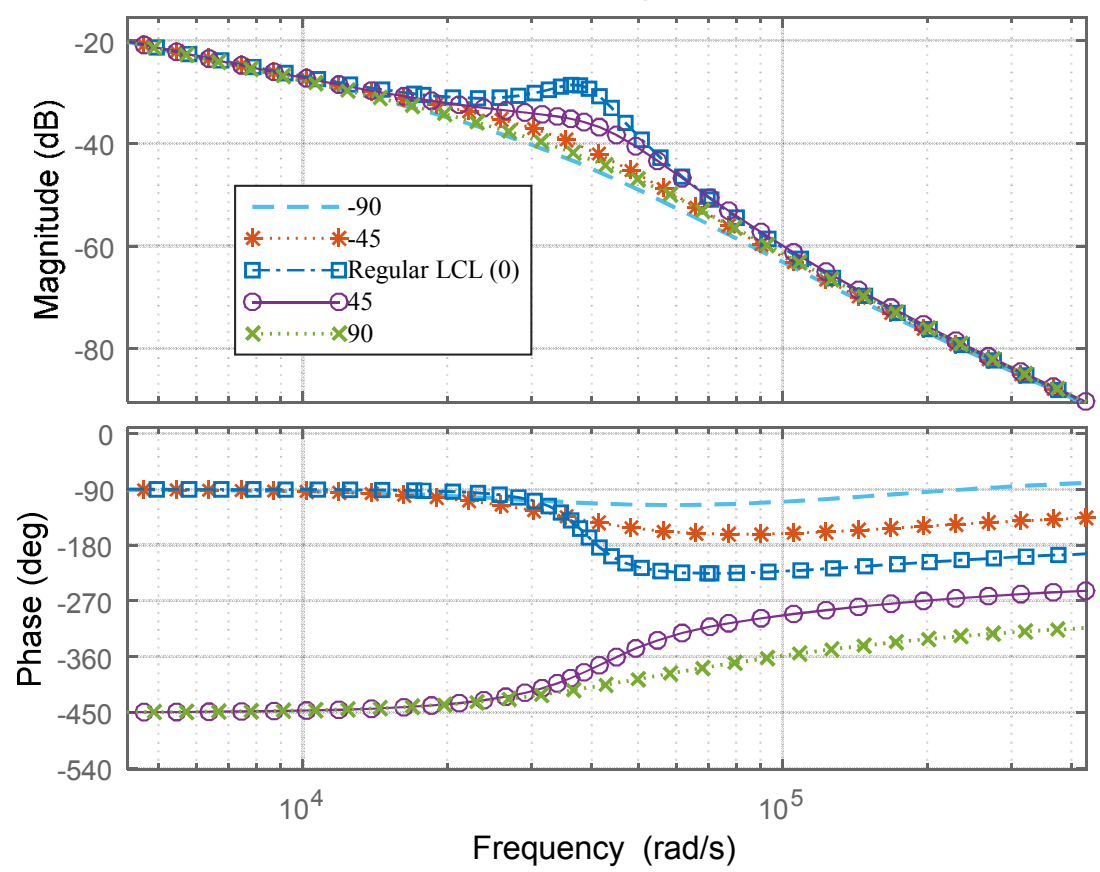

Figure 2. Bode plots of PST-LCL for different phase shifts.

\section{Filter Design Procedure}

Several specifications to design an LCL filter must be considered, such as the filter size, switching ripple attenuation [19], maximum current ripple, or phase of the parallel capacitor branch on the filter. Passive or active damping, described in [20] and [21] respectively, are often 
placed in series with the capacitor to prevent potential resonances of the capacitor interacting with the grid, and caused by reactive power requirements. Data for the filter design are defined as $\mathrm{P}_{\mathrm{n}}$, rated active power, $\mathrm{V}_{\mathrm{LL}}$, line-to-line RMS voltage (inverter output), $\mathrm{V}_{\mathrm{ph}}$, phase voltage (inverter output), $\mathrm{V}_{\mathrm{dc}}$, DC-link voltage, $\mathrm{f}_{\mathrm{sw}}$, switching frequency, $\mathrm{f}_{\mathrm{g}}$, grid frequency, $f_{\text {res }}$, resonance frequency. The base impedance and capacitance are calculated as $\mathrm{Z}_{\mathrm{b}}=\mathrm{E}_{\mathrm{n}}^{2} / \mathrm{P}_{\mathrm{n}}$ and $C_{b}=1 /\left(\omega_{g} \cdot Z_{b}\right)$, where $P_{n}$ is the rated active power absorbed by the converter, $E_{n}$ is the line to line rms voltage, and $\omega_{\mathrm{n}}$ is the grid frequency. Also, $\omega_{\text {res }}=\mathrm{k} \omega_{\mathrm{sw}}$, where $\omega_{\text {res }}$ and $\omega_{\text {sw }}$ are the resonance frequency and switching frequency respectively. Coefficient $\mathrm{k}$ represents the ratio of these two frequencies. The maximum power factor variations seen by the grid is assumed to be less than $5 \%$. It means that the base impedance of the system is set to $5 \%$ of the base capacitor. A simplified circuit of the inverter shown in Figure 3 is employed for the design of the inverter-side inductor [22]. Equations (3)-(6) apply to three phase inverter [23]. The maximum peak-to-peak current ripple occurs at $\mathrm{m}=0.5$. The maximum per-unit ripple can be assumed between $5 \%$ and $25 \%$. Let the ripple be $10 \%$ of the rated current, that is, $\Delta \mathrm{I}_{\mathrm{L}_{\max }}=0.1 \mathrm{I}_{\mathrm{L}_{\max }}$. The maximum peak-to-peak current ripple occurs at $\mathrm{m}=0.5$. Therefore, $\mathrm{L}_{\mathrm{I}}$ can be derived from (6), where $V_{d c}$ is the dc-link voltage, $f_{s w}$ is the switching frequency, and $V_{p h}$ is the phase voltage. The total inductance should be less than 0.1 p.u., because it may cause a drop of the ac voltage. Otherwise, a higher dc-link voltage would be required, which results in higher switching losses. The expected current ripple should be reduced to $20 \%$ by The LCL filter, which limits the ripple value to $2 \%$ of the output current [8]. In order to calculate the ripple reduction, the equivalent circuit of LCL filter is initially analyzed while the inverter is considered as a current source for each harmonic frequency. Equation (7) below gives the relation between the harmonic current generated by the inverter and the one injected in the grid (respectively $i_{I}(h)$ and $i_{G}(h)$ ). Simplifying this equation, results in (8) that represents the ripple attenuation factor. Equations (7) and (8) relate the harmonic current generated by the inverter with the one injected to the grid. Where $x$ is the maximum power factor variation seen by the grid and the constant $r$ is the ratio between the inductance at the inverter side and the one at the grid side. Then, $L_{G}$ can be found from (9) where $k a$ is the desired attenuation. The transfer function of the filter at a particular resonant frequency can be evaluated by plotting the results for several values of $r$, depending on the nominal grid impedance [24].

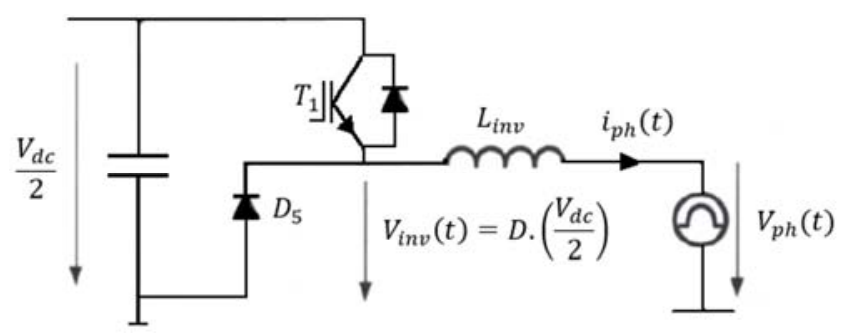

Figure 3. Simplified circuit of an inverter.

$$
\begin{gathered}
\Delta I_{L_{\text {max }}}=\frac{2 V_{d c}}{3 L_{I}}(1-m) m T_{s w} \\
\Delta I_{L_{\max }}=\frac{V_{d c}}{6 \cdot f_{s w} \cdot L_{I}} \\
\mathrm{I}_{\max }=\frac{P_{n} \sqrt{2}}{3 V_{p h}} \\
\mathrm{~L}_{\mathrm{I}}=\frac{V_{d c} \cdot V_{p h}}{2 \sqrt{2} \cdot f_{s w} \cdot P_{n}} \\
\frac{i_{G}(h)}{i_{I}(h)} \approx \frac{z_{L C}^{2}}{\left|\omega_{r e s}^{2}-\omega_{s w}^{2}\right|} \\
\frac{i_{G}(h)}{i_{I}(h)}=\frac{1}{\left|1+r\left[1-L_{I} \cdot C_{b} \cdot \omega_{s w}^{2} \cdot x\right]\right|} \\
L_{G}=\frac{\sqrt{\frac{1}{k_{a}^{2}}+1}}{C_{f} \cdot \omega_{s w}^{2}} \\
f_{r e s}=\frac{1}{2 \pi} \sqrt{\frac{L_{I}+L_{G}}{L_{I} \cdot L_{G} \cdot C_{f}}} \\
10 . f_{G}<f_{r e s}<0.5 f_{s w} \\
R_{f}=\frac{1}{3 \omega_{r e s} \cdot C_{f}}
\end{gathered}
$$

For effective attenuation, damping is needed as the transfer function of the filter peaks at certain frequencies, which may increase the ripple [23]. The resonant frequency can be calculated from formula (10) below, and it should be between ten times the grid frequency and a half of the switching frequency as stated in (11) to avoid resonance problems where $f_{g}$ is the grid frequency, $f_{\text {res }}$ is the resonant frequency, and $f_{s w}$ is the switching frequency. To avoid the resonance, a damping resistance is added in series with the capacitor attenuates part of the ripple at the switching frequency. As shown in (12), One third of the impedance of the filter capacitor at the resonant frequency can be taken as the damping resistance $R_{f}$ [25]. In this section, a PST is inserted in series into the $R_{f}-C_{f}$ branch. PSTs have been used to decrease the THD. Low-order harmonics of the input current, the fifth harmonic in particular, are minimized by PSTs in [26]. The input power factor is improved and the THD of the input current is reduced by a PST in [27]. However the large size and weight are considered as its disadvantages. In this paper, the PST is employed to minimize the filter impedance at the switching frequency. Figure 4 shows the simplified circuit of the proposed LCL filter, where $I_{h}$ is the harmonic current (assumed to be less than $5 \%$ of the main current), $\Phi$ is the phase-angle difference between $I_{h}$ and the grid voltage, and $\theta$ is the phase angle of the PST. Figure 5 shows phase diagrams for different phase angles at the switching frequency. The goal is to minimize harmonic currents at the switching frequency. Equations (13) and (14) define the phase angle, $\delta$, between $V$ and $V_{\text {Grid }}$ caused by the harmonic currents at the switching frequency. 


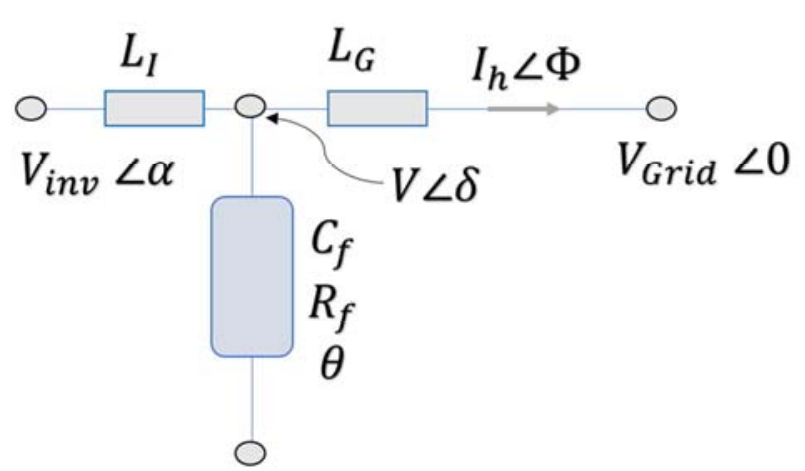

Figure 4. Simplified circuit of the proposed LCL filter.

$$
\begin{gathered}
\delta_{a}=\cot ^{-1}\left(\frac{\left|V_{\text {Grid }}\right|}{\omega_{s w} \cdot L_{G} \cdot\left|I_{h}\right|} \cdot \sec (\Phi)+\tan (\Phi)\right) \\
\delta_{\mathrm{b}}=\cot ^{-1}\left(\frac{\left|V_{G r i d}\right|}{\omega_{s w} \cdot L_{G} \cdot\left|I_{h}\right|} \cdot \sec (\Phi)-\tan (\Phi)\right)
\end{gathered}
$$

Therefore, the phase angle of the phase shifter transformer, $\theta$, should be optimized. The phase angle of the voltage across the $R_{f}-C_{f}$ branch should be the same as the phase angle of the impedance of that branch. Thus, the phase shift $\theta$ of the PST should equal the difference of the phase angle of the $C_{f}-R_{f}$ branch and the phase angle of V. Consequently, the optimum value of $\theta$ is given by

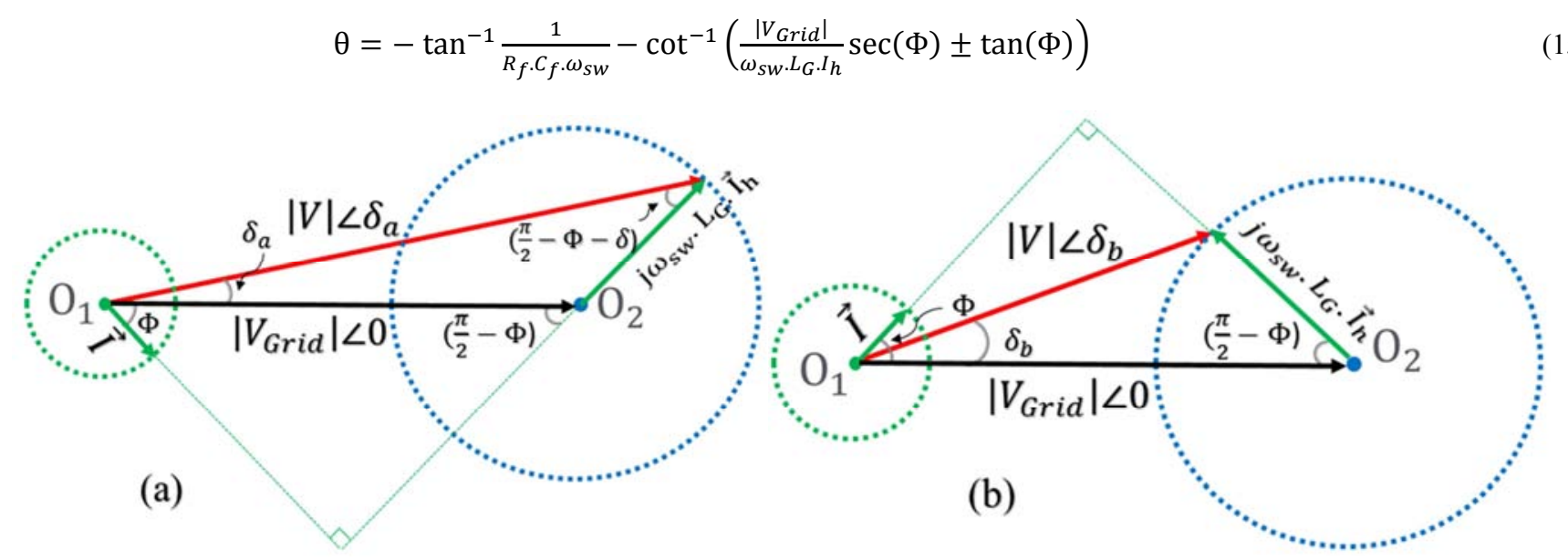

Figure 5. Phasor diagrams of the LCL filter at the switching frequency: (a) lagging current, (b) leading current.

\section{Simulation Results}

Figure 6 illustrates the case study. The 250-kW SunPower SPR-415E-WHT-D source consists of 88 seven-module strings. Specifications of this PV array are listed in Table 1.

\section{Inverter Control}

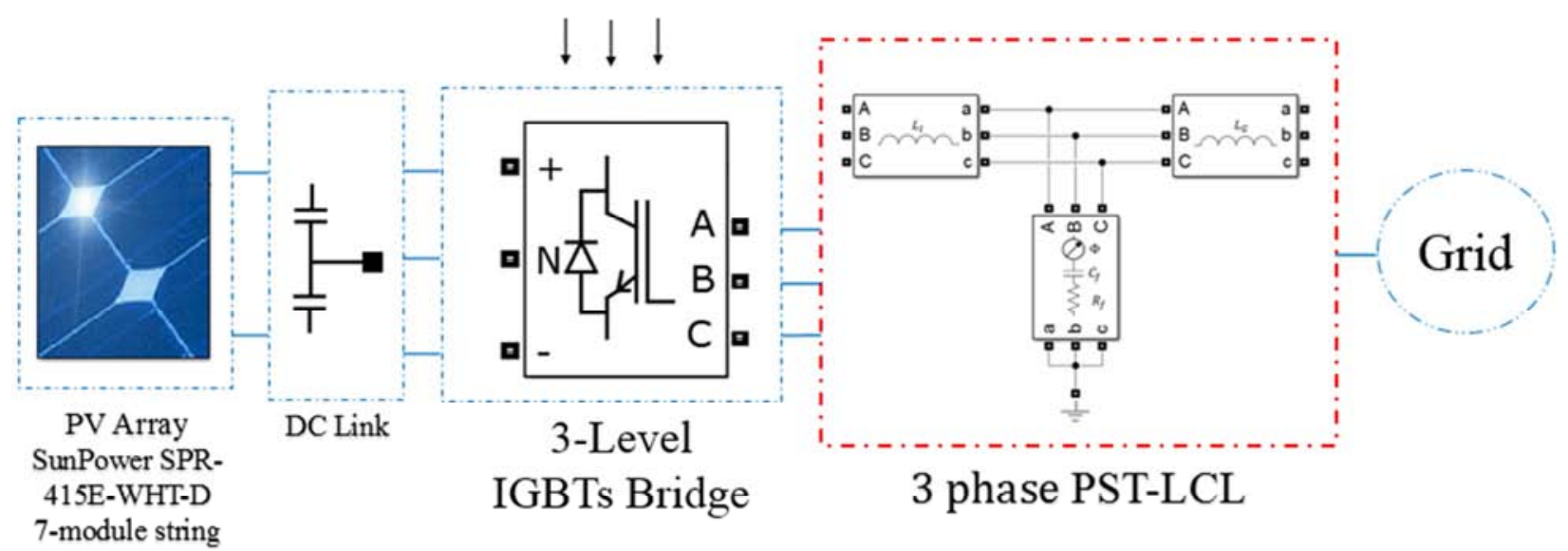

Figure 6. System in the Case Study.

Grid structure in the case study is shown in Figure 7. Table 2 lists specifications of the grid. Two 4-nF stray capacitances are located directly after the PV cells. A DC link stabilizes the DC voltage supplying three VSIs. The bipolar PWM method is employed. The grid voltage is $249 \mathrm{~V}$. The step-bystep design of the PST-LCL is outlined subsequently. System specifications are: $P_{S}=P_{n}=250 \mathrm{~kW}, E_{n}=249 \mathrm{~V}, V_{D C}=$ 
$482 \mathrm{~V}, f_{s w}=1980 \mathrm{~Hz}, \omega_{g}=2 \pi .60 \mathrm{rad} / \mathrm{s}, \quad x=0.05$, and $k_{a}=20 \%$, Consequently, the base impedance and capacitance are $Z_{S}=0.25 \Omega$, and $C_{B}=10.6 \mathrm{mF}$. Assuming the $10 \%$ allowed ripple, Eq. (6) yields $L_{I}=1.36 \mathrm{mH}$. In order to be within the limit of $5 \%$ of the base value of $C_{B}$, the maximum capacitor value, $C_{f}$, is set to $0.53 \mathrm{mF}$. For the desired attenuation factor, $L_{G}$ is found from Eq. (9) to be
$0.073 \mathrm{mH}$. Substituting the calculated parameters of $L_{I}, C_{f}$, and $L_{G}$ into Eq. (10) gives $f_{\text {res }}=830.49 \mathrm{~Hz}$, which meets condition (11). Eq. (14) determines the damping resistance $R_{f}=0.12 \Omega$. Angle $\Phi$ equals $40^{\circ}$, making $\delta_{b}=3.47^{\circ}$. The phase angle of the $C_{f}-R_{f}$ branch is $-51.64^{\circ}$ and, from Eq. (15), the phase angle of the PST is $-55.11^{0}$.

Table 1. The case study parameters.

\begin{tabular}{llll}
\hline $\begin{array}{l}\text { PV Array } \\
\text { Trina Solar TSM-250PA05.08 }\end{array}$ & & & \\
\hline Irradiance $\left(W / m^{2}\right)$ & 950 & Max Power (W) & 414.801 \\
Temperature (Deg. C) & 43 & Cells per module (Ncell) & 128 \\
Open Circuit Voltage (V) & 85.3 & Short-Circuit Current (A) & 6.09 \\
Voltage at maximum power point Vmp (V) & 72.9 & Current at maximum power point Imp (A) & 5.69 \\
Light-generated current IL(A) & 6.09 & Shunt Resistance Rsh (Ohms) & 419.8 \\
Diode Ideality Factor & 0.9977 & Parallel & 88 \\
Series Resistance Rs(Ohms) & 0.25 & Series & 7 \\
De Link \& Stray Capacitance & & & $2.87 \mathrm{e}-3$ \\
\hline Stray Capacitance & & DC Link & 425 \\
Capacitance (F) & $4 \mathrm{e}-9$ & Capacitance (F) & 60 \\
Inverter Control & & Capacitor initial voltage (V) & 480 \\
\hline Power (KVA) & 250 & Frequency (Hz) & {$[357,583]$} \\
Primary voltage (Vrms LL) & $25 \mathrm{~K}$ & DC voltage (V) & 1980 \\
Secondary voltage (Vrms LL) & 249.8 & Output limits (V) & \\
Output increment (V) & 0.01 & Carrier frequency (Hz) & 0.25 \\
DC Voltage Controller & & Current Regulator & 18 \\
Proportional gain & 1.5 & Proportional gain & \\
Integral gain & 387 & Integral gain & \\
\hline
\end{tabular}

Table 2. The specification of the grid in the case study.

\begin{tabular}{|c|c|c|c|}
\hline Three Phase Source & & & \\
\hline Phase-to-phase rms voltage (KV) & 122.4 & 3-phase short-circuit level at base voltage(MVA) & 2500 \\
\hline Base voltage rms $(\mathrm{KV})$ & 120 & $\mathrm{X} / \mathrm{R}$ ratio & 7 \\
\hline Three Phase Transformer A $(Y / \Delta)$ & & & \\
\hline Nominal power (MVA) & 47 & Frequency $(\mathrm{Hz})$ & 60 \\
\hline $\begin{array}{l}\text { Winding } 1 \text { ( V1 rms [120 KV], R1(pu) [0.0003], L1(pu) [0.08]) } \\
\text { Winding } 2 \text { ( V2 rms [25 KV], R2(pu) [0.0003], L2(pu) [0.08]) }\end{array}$ & & & \\
\hline $\begin{array}{l}\text { Load A: } 250 \mathrm{KW} \\
\text { Three Phase Transformer B }(\boldsymbol{Y} / \boldsymbol{\Delta})\end{array}$ & & Load C: $30 \mathrm{MW}$ and $2 \mathrm{Mvar}$ & \\
\hline $\begin{array}{l}\text { Nominal power (KVA) } \\
\text { Winding 1: ( V1 rms [25 KV], R1(pu) [0.0012], L1(pu) [0.03]) } \\
\text { Winding 2: ( V2 rms [249.8 V], R2(pu) [0.0012], L2(pu) [0.08]) } \\
\text { Feeder A: } 14 \mathrm{Km} \mathrm{R}: 0.115(\mathrm{Ohms} / \mathrm{km}), \mathrm{L}: 1.05(\mathrm{mH} / \mathrm{km}), \mathrm{C}: 11.33(\mathrm{nF} / \mathrm{km}) \\
\text { Feeder B: } 8 \mathrm{Km} \text { R:0.115(Ohms/km), L: } 1.05(\mathrm{mH} / \mathrm{km}), \mathrm{C}: 11.33(\mathrm{nF} / \mathrm{km})\end{array}$ & 250 & Frequency $(\mathrm{Hz})$ & 60 \\
\hline
\end{tabular}

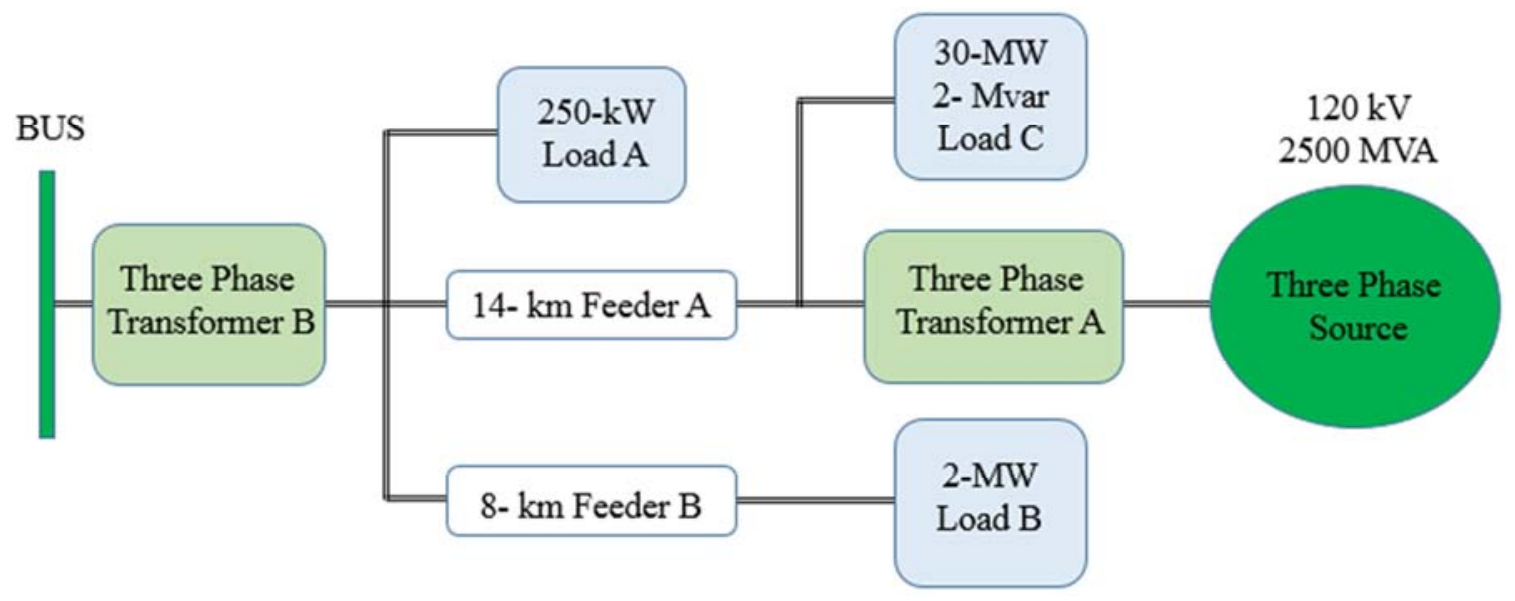

Figure 7. Grid structure in the case study. 

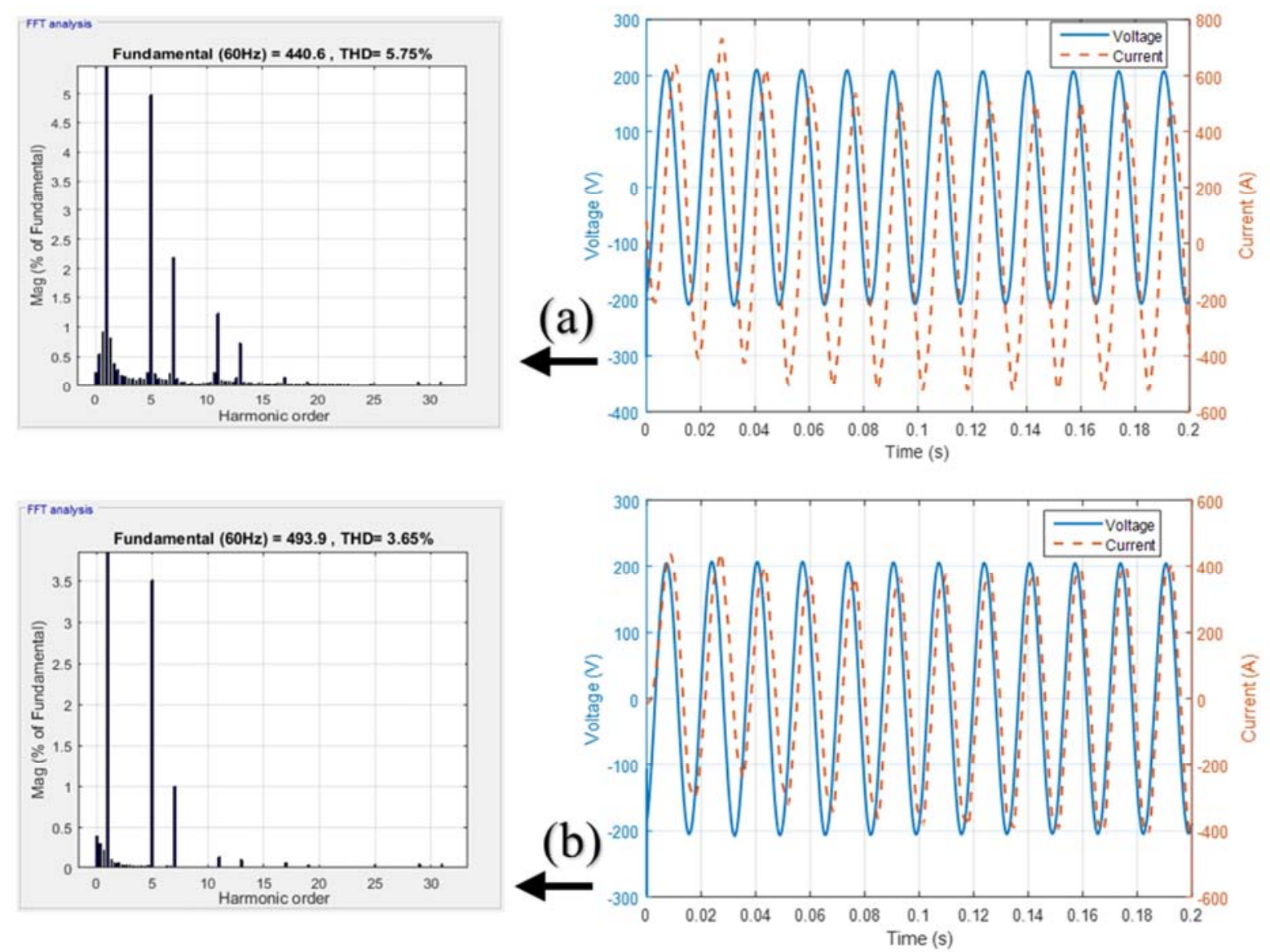

Figure 8. Currents injected into grid-FFTs and waveforms: (a) LCL filter, (b) PST-LCL filter.

Comparative FFT analysis for the LCL and PST-LCL filters is illustrated in Figure 8. The THD in presence of the LCL filter is $5.75 \%$, and it decreases to $3.6 \%$ for the PSTLCL one. Figure 8 also shows waveforms of voltage and current in the inverter. It can be observed that, compared to the regular LCL filter, the harmonic currents in presence of the proposed filter has been considerable reduced.

\section{Conclusion}

A new approach to mitigate harmonic currents in threephase grid-connected PV sources has been proposed. A phase shifting transformer is added into the regular LCL filter structure which enhances the filter performance. Harmonic currents are greatly reduced improving operation of the involved utility grid. The proposed is fully controllable which allows reducing the current THD to a desired range. The comprehensive design procedure of the PST-LCL filter has been described in detail.

\section{References}

[1] Rashid Niaz Azari, Mohammad Amin Chitsazan, Iman Niazazari. Optimal Recloser Setting, Considering Reliability and Power Quality in Distribution Networks. American Journal of Electrical Power and Energy Systems. Vol. 6, No. 1, 2017, pp. 1-6.
[2] M. A. Chitsazan, M. Sami Fadali, Amanda K. Nelson, A. M Trzynadlowski, "Wind speed forecasting using an echo state network with nonlinear output functions", American Control Conference (ACC), 2017 IEEE, pp. 5306-5311, May. 2017.

[3] M. A. Chitsazan, A. M Trzynadlowski, "State estimation of IEEE 14 bus with interphase power controller using WLS method", Energy Conversion Congress and Exposition (ECCE), 2016 IEEE, pp. 1-5, Sep. 2016.

[4] F. Blaabjerg, T. Teodorescu, M. Liserre, and A. V. Timbus, "Overview of control and grid synchronization for distributed power generation systems," IEEE Trans. Ind. Electron., vol. 53, no. 5, pp. 1398-1409, Oct. 2006.

[5] J. He, Y. Li, and M. S. Munir, "A flexible harmonic control approach through voltage-controlled DG-grid interfacing converters," IEEE Trans. Ind. Electron., vol. 59, no. 1, pp. 444-455, Jan. 2012.

[6] M. Liserre, F. Blaabjerg, and S. Hansen, "Design and control of an LCL filter-based three-phase active rectifier", IEEE Trans. Ind. Appl., vol. 41, no. 5, pp. 1281-1291, Sep./Oct. 2005.

[7] Y. Tang, S. Member, P. C. Loh, P. Wang, and F. H. Choo, "Generalized design of high performance shunt active power filter with output LCL filter", IEEE Trans. Ind. Electron., vol. 59, no. 3, pp. 1443-1452, Mar. 2012.

[8] IEEE Recommended Practices and Requirements for Harmonic Control in Electrical Power Systems, IEEE Std 5191992, 1993. 
[9] IEEE Standard Conformance Test Procedures for Equipment Interconnecting Distributed Resources with Electric Power Systems, IEEE Std 1547.1-2005, 2005.

[10] F. Huerta, D. Pizarro, S. Cobreces, F. J. Rodriguez, C. Giron, and A. Rodriguez, "LQG servo controller for the current control of LCL grid connected voltage-source converters," IEEE Trans. Ind. Electron., vol. 59, no. 11, pp. 4272-4284, Nov. 2012.

[11] P. Channegowda and V. John, "Filter optimization for grid interactive voltage source inverters", IEEE Trans. Ind. Electron., vol. 57, no. 12, pp. 4106-4114, Dec. 2010.

[12] Y. Tang, P. Loh, P. Wang, F. Choo, F. Gao, and F. Blaabjerg, "Generalized design of high performance shunt active power filter with output LCL-filter", IEEE Trans. Ind. Electron., vol. 59, no. 3, pp. 1443-1452, Mar. 2012.

[13] A. M. Hava, T. A. Lipo, and W. L. Erdman, "Utility interface issues for line connected PWM voltage source converters: a comparative study", in Proc. of APEC '95, Dallas (USA), pp. 125-132, March 1995.

[14] U. N. Khan and T. S. Sidhu, "A phase-shifting transformer protection technique based on directional comparison approach", IEEE Trans. on Power Delivery, vol. 29, no. 5, pp. 2315-2323, Sep. 2014.

[15] J. Bladow and A. Montoya, "Experiences with parallel EHV shifting transformers", IEEE Trans. on Power Delivery, vol. 6, no. 3, pp. 1096-1100, July 1991.

[16] M. A. Chitsazan, G. Gharehpetian, M. Arbabzadeh, "Application of voltage source convector in interphase power controller", Proc. of World Congress on Engineering and Computer Science (WCECS), vol. 2, pp. 1-6, Oct. 2012.

[17] M. A. Chitsazan, A. M Trzynadlowski, "Harmonic mitigation in interphase power controllers using passive filter-based phase shifting transformer", Energy Conversion Congress and Exposition (ECCE), 2016 IEEE, pp. 1-5, Sep. 2016.

[18] Mohammad Amin Chitsazan, Andrzej M. Trzynadlowski. A New Approach to LCL Filter Design for Grid-Connected PV
Sources. American Journal of Electrical Power and Energy Systems. Vol. 6, No. 4, 2017, pp. 57-63.

[19] A. Reznik, M. G. Simoes, A. Al-Durra, S. M. Muyeen, "Filter design and performance analysis for grid-interconnected systems", IEEE Trans. on Ind. Appl., vol. 50, no. 2, pp. 1225, 1232, March-April 2014.

[20] H. Cha and T.-K. Vu, "Comparative analysis of low-pass output filter for single-phase grid-connected photovoltaic inverter," in Proc. APEC'10, Palm Springs, CA, pp. 16591665, Feb. 2010.

[21] F. Bouchafaa, D. Beriber, and M. S. Boucherit, "Modeling and control of a grid connected PV generation system", in Proc. MED'10, Marrakesh, Morocco, pp. 315-320, Jun. 2010.

[22] V. H. Prasad, "Average Current Mode Control of a Voltage Source Inverter Connected to the Grid: Application to Different Filter Cells", M. S. thesis, Dept. Elect. Eng., Virginia Polytech. Inst. State Univ., Blacksburg, VA, USA, 1997.

[23] D. E. Rice, "A detailed analysis of six-pulse converter harmonic currents" IEEE Trans. Ind. Appl., vol. 30, no. 2, pp. 294-304, March/April, 1994.

[24] S. V. Araujo, A. Engler, B. Sahan, and F. Antunes, "LCL filter design for grid-connected NPC inverters in offshore wind turbines", in Proc. ICPE '07, Daegu, S. Korea, pp. 1133-1138, Oct. 2007.

[25] M. Grötzbach, and R. Redmann, "Line current harmonics of VS1-fed adjustable-speed drives," IEEE Trans. Ind. Appl., vol. 36, no. 2, pp. 683-690, March/April, 2000.

[26] C. Rech and J. R. Pinheiro, "Line current harmonics reduction in hybrid multilevel converters using phase-shifting transformers," in Proc. PESC'04, Aachen Germany, pp. 25652571, Jun. 2004.

[27] D. A. Paice, "Power Electronic Converter Harmonics Multipulse Methods for Clean Power”, IEEE Press, 1996. 